\title{
Comparison of the Prognostic Value of Inflammation-Based Scores in Patients with Hepatocellular Carcinoma After Anti-PD-I Therapy
}

\author{
Jie Mei iD ${ }^{1,2, *}$ \\ Xu-Qi Sun ${ }^{3, *}$ \\ Wen-Ping Lin ${ }^{1,2, *}$ \\ Shao-Hua $\mathrm{Li}^{1,2}$ \\ Liang-He Lu ${ }^{1,2}$ \\ Jing-Wen Zou ${ }^{1,2}$ \\ Wei Wei ${ }^{1,2}$ \\ Rong-Ping Guo (D) ${ }^{1,2}$ \\ 'Department of Liver Surgery, Sun Yat-sen \\ University Cancer Center, Guangzhou, \\ People's Republic of China; ${ }^{2}$ State Key \\ Laboratory of Oncology in South China, \\ Collaborative Innovation Center for \\ Cancer Medicine, Guangzhou, People's \\ Republic of China; ${ }^{3}$ Department of \\ Hepatobiliary and Pancreatic Surgery, The \\ First Affiliated Hospital, Zhejiang \\ University School of Medicine, Hangzhou, \\ People's Republic of China
}

*These authors contributed equally to this work
Correspondence: Rong-Ping Guo; Wei

Wei

Email guorp@sysucc.org.cn;

weiwei@sysucc.org.cn
Background: Inflammatory response is related to cancer progression and patient survival. However, the value in predicting survival in hepatocellular carcinoma (HCC) patients who received anti-PD-1 therapy has not been elucidated. This study aimed to compare the predictive ability of inflammation-based scores for the prognosis of HCC patients after antiPD-1 therapy.

Methods: A total of 442 patients who received anti-PD-1 therapy were included in the study. Representative inflammation-based prognostic scores, including the platelet-tolymphocyte ratio (PLR), neutrophil-to-lymphocyte ratio (NLR), lymphocyte-to-C-reactive protein (CRP) ratio (LCR), lymphocyte-to-monocyte ratio (LMR), systemic immune inflammation index (SII), CRP-to-albumin ratio (CAR), prognostic nutritional index (PNI), Glasgow Prognostic Score (GPS), modified Glasgow Prognostic Score (mGPS), and prognostic index (PI), were assessed for prediction accuracy using Kaplan-Meier survival curves, time-dependent receiver operating characteristic (ROC) and Harrell's concordance index (C-index) analyses.

Results: All the inflammation-based prognostic scores exhibited good discriminatory ability in overall survival (OS) (all $\mathrm{P}<0.01$ ), while the PNI score was a unique independent predictor for OS in multivariate analysis (hazard ratio, 1.770; confidence interval, 1.3092.393; $\mathrm{P}<0.001)$. The areas under the ROC curves at $6,12,18$ and 24 months and the C-index (0.65) demonstrated that the predictive accuracy of the PNI score was superior to that of the other inflammation-based scores.

Conclusion: The PNI score is a discriminatory prognostic indicator for OS in HCC patients with anti-PD-1 therapy and is superior to the other inflammation-based prognostic scores in terms of predictive ability.

Keywords: inflammation-based score, hepatocellular carcinoma, anti-PD-1 therapy, overall survival, prognostic nutritional index

\section{Introduction}

Hepatocellular carcinoma (HCC) is the most common types of liver cancer and the third leading cause of cancer-related deaths worldwide. ${ }^{1}$ Due to its uneventful onset and rapid progression, most patients with HCC fail to meet the criteria for radical resection. $^{2}$ In recent years, research on programmed cell death protein-1 (PD-1) inhibitors has continued to emerge, offering new treatment models for HCC patients. ${ }^{3}$ Given that nivolumab and pembrolizumab have shown certain efficacy and safety, anti-PD-1 therapy is commonly used as a treatment option for systemic 
therapy. ${ }^{4,5}$ However, the efficacy of immunotherapy varies greatly among individuals. Practical and reliable prognostic predictors are needed in anti-PD-1 treatment.

Inflammation is a hallmark of cancer. ${ }^{6}$ Emerging evidence shows that the host inflammatory response is related to cancer progression and patient survival. ${ }^{7,8}$ In immunotherapy, inflammation has a predominant role in tumor survival and proliferation, angiogenesis and immunosuppression. ${ }^{9}$ Recently, many inflammationbased prognostic scores composed of systemic inflammatory response factors, including platelet-tolymphocyte ratio (PLR), ${ }^{10}$ neutrophil-to-lymphocyte ratio (NLR), ${ }^{11}$ lymphocyte-to-C-reactive protein (CRP) ratio (LCR), ${ }^{12}$ lymphocyte-to-monocyte ratio $(\mathrm{LMR}),{ }^{13}$ systemic immune inflammation index (SII), ${ }^{14}$ CRP-to-albumin (ALB) ratio (CAR), ${ }^{15}$ prognostic nutritional index (PNI), ${ }^{16}$ Glasgow Prognostic Score (GPS), ${ }^{17}$ modified Glasgow Prognostic Score (mGPS), ${ }^{18}$ and prognostic Index (PI), ${ }^{19}$ were proposed to exhibit good predictive ability in cancer prognosis. High pre- and post-treatment NLR and PLR was reported to be associated with worse tumor response and increasing risk of death for anti-PD-1 treatment in HCC. ${ }^{20}$ Though, the value of inflammation-based scores in predicting survival after anti-PD-1 treatment in HCC patients has not been fully elucidated.

Herein, this study aimed to make a direct comparison of the prognostic value of various inflammation-based scores in HCC patients after anti-PD-1 therapy.

\section{Materials and Methods}

This study was conducted according to the ethical guidelines of the 1975 Declaration of Helsinki. The analysis of patient data was reviewed and approved by the Institutional Review Board and Human Ethics Committee at the Sun Yat-sen University Cancer Center (SYSUCC; Guangzhou, China, B2020-190-01).

\section{Patients}

Between July 2018 and December 2019, patients diagnosed with HCC who received anti-PD-1 therapy at SYSUCC were screened for eligibility. Patients were included based on the following criteria: (a) diagnosed with HCC through imaging or pathology according to the American Association for the Study of Liver Diseases (AASLD) practice guidelines; ${ }^{21}$ (b) had confirmed records of receiving PD-1 inhibitors; (c) aged from 18 to 75 years; (d) had a performance status (PS) score less than 2 and a Child-Pugh (CP) stage of A or B; (e) had no other malignant tumors; and (f) had complete medical and follow-up data. All laboratory serum test data were collected within 3 days before the initial use of PD-1 inhibitors. Imaging evaluation included enhanced computed tomography (CT) or magnetic resonance imaging (MRI) examination within a week before the administration of anti-PD-1 therapy.

\section{Treatment Procedure}

PD-1 inhibitors were administered intravenously with saline. The types and dosages of drugs are summarized in Table S1. PD-1 inhibitors could be combined with locoregional interventional therapies or tyrosine kinase inhibitors (TKIs) including sorafenib, lenvatinib, regorafenib or apatinib during treatment. Drug discontinuation was applied upon disease progression, the development of unacceptable toxicity, patient withdrawal of consent, or changes in the treatment plan.

\section{Inflammation-Based Prognostic Scores}

The counts of white blood cells, neutrophils, lymphocytes, monocytes, and platelets and the levels of CRP and ALB were obtained through routine laboratory tests of blood samples. The PLR, NLR, LCR, LMR, SII, CAR, GPS, mGPS, PI and PNI were calculated as described in Table 1.

\section{Follow-Up and Definitions}

The final follow-up ended on March 31, 2021. Follow-up examinations were conducted using laboratory tests including serum alpha fetoprotein (AFP), liver function, and routine blood tests. Abdominal ultrasonography, enhanced CT or MRI was performed every 1 to 2 months after the receipt of PD-1 inhibitors. Follow-up intervals were routinely 2 to 4 months.

Tumor response was defined as complete response (CR), partial response (PR), stable disease (SD), or progressive disease (PD) according to the modified Response Evaluation Criteria in Solid Tumors 1.1 (mRECIST). ${ }^{22}$ Overall survival (OS) was defined as the time interval from anti-PD-1 initiation to cancerrelated death.

\section{Statistical Analysis}

The results are described using the median and range for nonnormally distributed values. 
Table I Systemic Inflammation-Based Prognostic Scores

\begin{tabular}{|c|c|}
\hline Scoring System & Score \\
\hline \multicolumn{2}{|l|}{ Platelet to lymphocyte ratio (PLR) } \\
\hline Platelet count $\left(\times 10^{9} / \mathrm{L}\right)$ : lymphocyte count $\left(\times 10^{9} / \mathrm{L}\right)<136.8$ & 0 \\
\hline Platelet count $\left(\times 10^{9} / \mathrm{L}\right)$ : lymphocyte count $\left(\times 10^{9} / \mathrm{L}\right) \geq 136.8$ & I \\
\hline \multicolumn{2}{|l|}{ Neutrophil to lymphocyte ratio (NLR) } \\
\hline Neutrophil count $\left(\times 10^{9} / \mathrm{L}\right)$ : lymphocyte count $\left(\times 10^{9} / \mathrm{L}\right)<3.3$ & 0 \\
\hline Neutrophil count $\left(\times 10^{9} / \mathrm{L}\right)$ : lymphocyte count $\left(\times 10^{9} / \mathrm{L}\right) \geq 3.3$ & I \\
\hline \multicolumn{2}{|l|}{ Lymphocyte to C-reactive protein ratio (LCR) } \\
\hline $10^{4} \times$ lymphocyte count $\left(\times 10^{9} / \mathrm{L}\right):$ CRP $(\mathrm{mg} / \mathrm{L}) \geq 2247.3$ & 0 \\
\hline $10^{4} \times$ lymphocyte count $\left(\times 10^{9} / \mathrm{L}\right): \mathrm{CRP}(\mathrm{mg} / \mathrm{L})<2247.3$ & I \\
\hline \multicolumn{2}{|l|}{ Lymphocyte to monocyte ratio (LMR) } \\
\hline Lymphocyte count $\left(\times 10^{9} / \mathrm{L}\right):$ monocyte count $\left(\times 10^{9} / \mathrm{L}\right) \geq 3.5$ & 0 \\
\hline Lymphocyte count $\left(\times 10^{9} / \mathrm{L}\right):$ monocyte count $\left(\times 10^{9} / \mathrm{L}\right)<3.5$ & I \\
\hline \multicolumn{2}{|l|}{ Systemic Immune-inflammation Index (SII) } \\
\hline Platelet count $\left(\times 10^{9} / \mathrm{L}\right) \times$ neutrophil count $\left(\times 10^{9} / \mathrm{L}\right) /$ lymphocyte count $\left(\times 10^{9} / \mathrm{L}\right)<268.8$ & 0 \\
\hline Platelet count $(\times 109 / \mathrm{L}) \times$ neutrophil count $(\times 109 / \mathrm{L}) /$ lymphocyte count $(\times 109 / \mathrm{L}) \geq 268.8$ & 1 \\
\hline \multicolumn{2}{|l|}{ CRP to albumin ratio (CAR) } \\
\hline CRP $(\mathrm{mg} / \mathrm{L}):$ albumin $(\mathrm{g} / \mathrm{L})<0 . \mathrm{I}$ & 0 \\
\hline CRP $(\mathrm{mg} / \mathrm{L}):$ albumin $(\mathrm{g} / \mathrm{L}) \geq 0.1$ & I \\
\hline \multicolumn{2}{|l|}{ Glasgow Prognostic Score (GPS) } \\
\hline CRP $\leq 10 \mathrm{mg} / \mathrm{L}$ and albumin $\geq 35 \mathrm{~g} / \mathrm{L}$ & 0 \\
\hline $\mathrm{CRP} \leq 10 \mathrm{mg} / \mathrm{L}$ and albumin $<35 \mathrm{~g} / \mathrm{L}$ & I \\
\hline CRP $>10 \mathrm{mg} / \mathrm{L}$ and albumin $\geq 35 \mathrm{~g} / \mathrm{L}$ & I \\
\hline $\mathrm{CRP}>10 \mathrm{mg} / \mathrm{L}$ and albumin $<35 \mathrm{~g} / \mathrm{L}$ & 2 \\
\hline \multicolumn{2}{|l|}{ Modified Glasgow Prognostic Score (mGPS) } \\
\hline $\mathrm{CRP} \leq 10 \mathrm{mg} / \mathrm{L}$ and albumin $\geq 35 \mathrm{~g} / \mathrm{L}$ & 0 \\
\hline $\mathrm{CRP} \leq 10 \mathrm{mg} / \mathrm{L}$ and albumin $<35 \mathrm{~g} / \mathrm{L}$ & 0 \\
\hline CRP $>10 \mathrm{mg} / \mathrm{L}$ and albumin $\geq 35 \mathrm{~g} / \mathrm{L}$ & I \\
\hline CRP $>10 \mathrm{mg} / \mathrm{L}$ and albumin $<35 \mathrm{~g} / \mathrm{L}$ & 2 \\
\hline \multicolumn{2}{|l|}{ Prognostic Index (PI) } \\
\hline $\mathrm{CRP} \leq 10 \mathrm{mg} / \mathrm{L}$ and $W B C$ count $\leq 10 \times 10^{9} / \mathrm{L}$ & 0 \\
\hline$C R P \leq 10 \mathrm{mg} / \mathrm{L}$ and $W B C$ count $>10 \times 10^{9} / \mathrm{L}$ & I \\
\hline CRP $>10 \mathrm{mg} / \mathrm{L}$ and $W B C$ count $\leq 10 \times 10^{9} / \mathrm{L}$ & I \\
\hline CRP $>10 \mathrm{mg} / \mathrm{L}$ and $W B C$ count $>10 \times 10^{9} / \mathrm{L}$ & 2 \\
\hline \multicolumn{2}{|l|}{ Prognostic Nutritional Index (PNI) } \\
\hline Albumin $(\mathrm{g} / \mathrm{L})+5 \times$ lymphocyte count $\left(\times 10^{9} / \mathrm{L}\right) \geq 48$ & 0 \\
\hline Albumin $(\mathrm{g} / \mathrm{L})+5 \times$ lymphocyte count $\left(\times 10^{9} / \mathrm{L}\right)<48$ & I \\
\hline
\end{tabular}

Abbreviations: CRP, C-reactive protein; WBC, white blood cell.

Groups were compared by using Student's $t$-test for continuous data and the $\chi^{2}$ test for categorical data. Survival analysis was performed using the KaplanMeier method, and differences in the survival curves were analyzed with the Log rank test. For single value indicators, to avoid deviations from different criteria for the cutoff values of the prognostic scores in this cohort, the optimal cutoff point was calculated using X-tile v.3.6.1 software for PLR, NLR, LCR, LMR, SII, CAR, and PNI (Figure S1). For composite indicators, the GPS, mGPS and PI scores were calculated as generally reported. ${ }^{17-19}$ Univariate and multivariate Cox regression analyses were performed to determine prognostic factors for OS. Hazard ratios (HRs) and 
confidence intervals $(\mathrm{CI})$ were also calculated. All variables with a $\mathrm{P}$-value $<0.05$ in the univariate analyses were used in the multivariate analyses using Cox proportional hazards models. A two-tailed P-value $<0.05$ was considered statistically significant. Time-dependent receiver operating characteristic (ROC) curves at 6,12 , 18 and 24 months and the area under the curve (AUC) were calculated to compare the predictive ability of the ten inflammation-based scores. Harrell's concordance index (C-index) was determined to evaluate the predictive ability of the ten inflammation-based scores. All data analyses were performed using SPSS 25.0 software (SPSS Inc., Chicago, IL), GraphPad Prism (version 8.0; GraphPad, Inc.) and $\mathrm{R}$ version 4.0.2.

\section{Result}

\section{Identification and Characteristics of the Study Patients}

From July 2018 to December 2019, a total of 442 patients who received anti-PD-1 therapy and met the criteria were included in the study. Among them, 382 (86.4\%) were males. Ages ranged from 21 to 75 years with a median of 52 years. Consistent with the characteristics of HCC in China, 372 (84.2\%) patients had hepatitis B. A majority of patients were classified as CP stage A (92.8\%) and BCLC stage C (72.2\%), and most had multiple tumors (67.9\%). A total of 232 $(52.5 \%)$ patients had macrovascular invasion, and 176 (39.8\%) patients had extrahepatic metastasis. The range of tumor size is from 1 to $21.5 \mathrm{~cm}$, with a median of $8.9 \mathrm{~cm}$. The clinical characteristics, including the ten inflammation-based scores of the patients, are summarized in Table 2.

Of note, most patients received another antitumor treatment before anti-PD-1 therapy, including surgery $(14.0 \%)$, transcatheter arterial chemoembolization (TACE) (20.4\%), hepatic infusion chemotherapy (HAIC) $(21.0 \%)$, ablation (8.1\%) and TKIs (11.3\%). The duration of anti-PD-1 therapy ranged from 1 to 18.9 months with a median of 5.7 months. The number of treatment cycles ranged from 1 to 25 with a median of 5. The types of PD-1 inhibitors included nivolumab (6.6\%), pembrolizumab (7.7\%), toripalimab (62.7\%), sintilimab (21.3\%) and camrelizumab (6.3\%) (Table S1). The median duration of follow-up was 13.7 months, while the median OS was 18.3 months. A total of 204 (46.2\%) patients died, while 195 (44.1\%) patients survived at the end of the follow-up.

\section{Independent Prognostic Factors for OS}

Univariate analysis involved prognostic factors related to ethnic characteristics, liver function, tumor burden, the treatment process and the ten inflammation-based scores.

In addition to liver function and tumor stage, all ten inflammation scores were identified as significant prognostic factors for OS. Multivariate analysis revealed that total bilirubin (TBIL) $(\mathrm{P}=0.025)$, Barcelona Clinic Liver Cancer $(\mathrm{BCLC})$ stage $(\mathrm{P}=0.003)$, largest tumor size $(\mathrm{P}<0.001)$, tumor number $(\mathrm{P}=0.001)$ and PNI $(\mathrm{P}<0.001)$ were independent prognostic factors for OS (Table 3).

\section{Overall Survival}

As shown in Figure 1, all inflammation-based scores were associated with the OS of patients who received anti-PD-1 therapy. High PLR, NLR, LCR, LMR, SII, CAR, GPS, mGPS, PI and PNI scores indicated poor prognosis (all $\mathrm{P}<$ 0.01). However, only the PNI score remained significant in multivariate analysis. The PNI score differentiated the HCC patients into two groups with distinct prognoses (6-, 12-, and 24-month OS rates: $90.9 \%, 71.7 \%$, and $51.5 \%$ and $77.6 \%, 50.7 \%$, and $25.7 \%$, respectively; $\mathrm{P}<$ $0.001)$.

\section{Comparison of the Performance of the Inflammation-Based Scores}

Time-dependent ROC curves at 6, 12, 18 and 24 months of OS were formed to compare the performance of the ten inflammation-based scores (Figure $\underline{\mathrm{S}}$ ), and the PNI score was superior to the others. The AUC of the time-dependent ROC curve showed that the PNI score had a better ability to predict OS. Plots of the time-dependent AUC are shown in Figure 2. The C-indexes were calculated, and the values are provided in Table 4 . The PNI scores consistently had higher C-index values than the other scoring systems. 
Table 2 Baseline Characteristics of the Enrolled Patients

\begin{tabular}{|c|c|}
\hline Variables & $N=442$ \\
\hline Age, y & $52(2 \mid-75)$ \\
\hline Gender (male/female) & $382 / 60(86.4 / 13.6)$ \\
\hline Hepatitis B (no/yes) & $372 / 70(84.2 / 15.8)$ \\
\hline HBV-DNA copies & $382\left(0-2.2 \times 10^{8}\right)$ \\
\hline WBC $\left(10^{9} / \mathrm{L}\right)$ & $6.4(2.3-17.2)$ \\
\hline ALT, U/L, $(\leq />50)$ & $44.0(5.6-520.3)$ \\
\hline AST, U/L, $(\leq />40)$ & $56.5(14.5-893.4)$ \\
\hline ALB, g/L, $(\leq />35)$ & $40.7(24.5-52.4)$ \\
\hline TBIL, umol/L, $(\leq />\mid 7.1)$ & | $5.0(4.0-|| 4.3)$ \\
\hline CRP, mg/L & II.5 (0.08-263.5) \\
\hline AFP, $n g / m L$ & $683.6(1.4-121,000.0)$ \\
\hline PIVKA-II, mAU/mL & $3628.0(16.0-75,000.0)$ \\
\hline Child-Pugh Grade (A/B) & $410 / 32(92.8 / 7.2)$ \\
\hline BCLC Stage $(A / B / C)$ & $39 / 84 / 319(8.8 / 19.0 / 72.2)$ \\
\hline Largest tumor size, $\mathrm{cm}$ & $8.9(|.0-2| .5)$ \\
\hline Tumor number $(I />1)$ & $142 / 300(32.1 / 67.9)$ \\
\hline Macrovessel invasion (no/yes) & $210 / 232(47.5 / 52.5)$ \\
\hline Extrahepatic metastasis (no/yes) & $266 / 176(60.2 / 39.8)$ \\
\hline $\operatorname{PLR}(0 / I)$ & $232 / 210(52.5 / 47.5)$ \\
\hline $\operatorname{NLR}(0 / I)$ & $277 / 165(62.7 / 37.3)$ \\
\hline $\operatorname{LCR}(0 / I)$ & $19|/ 25|(43.2 / 56.8)$ \\
\hline $\operatorname{LMR}(0 / I)$ & $224 / 198(50.2 / 44.8)$ \\
\hline SII $(0 / I)$ & $76 / 366(17.2 / 82.8)$ \\
\hline $\operatorname{CAR}(0 / 1)$ & $232 / 210(52.5 / 47.5)$ \\
\hline GPS $(0 / 1 / 2)$ & $2 / 3 / / 83 / 46(48.2 / 4 \mid .4 / 10.4)$ \\
\hline mGPS $(0 / 1 / 2)$ & I97/I99/46 (44.6/45.0/I0.4) \\
\hline $\mathrm{PI}(0 / \mathrm{I} / 2)$ & $|6| / 24 \mid / 40(36.4 / 54.5 / 9.0)$ \\
\hline PNI (0/I) & $229 / 2 \mid 3(5 \mid .8 / 48.2)$ \\
\hline Cycles of anti-PD-I & $4(I-25)$ \\
\hline \multicolumn{2}{|l|}{ Previous treatment } \\
\hline Surgery & $62(14.0)$ \\
\hline TACE & $90(20.4)$ \\
\hline HAIC & $93(21.0)$ \\
\hline
\end{tabular}

(Continued)
Table 2 (Continued).

\begin{tabular}{|l|c|}
\hline Variables & $\mathbf{N}=\mathbf{4 4 2}$ \\
\hline Ablation & $36(8.1)$ \\
\hline TKls* & $50($ II.3) \\
\hline
\end{tabular}

Notes: values are presented as the median (range) or $\mathrm{n}(\%)$. ${ }^{*}$ TKls include sorafenib, lenvatinib, regorafenib, apatinib.

Abbreviations: HBV, Hepatitis B virus; WBC, white blood cell; ALT, alanine aminotransferase; AST, aspartate aminotransferase; ALB, albumin; TBIL, total bilirubin; CRP, C-reactive protein; AFP, alpha fetoprotein; PIVKA-II, protein induced by vitamin K absence or antagonist-II; BCLC, Barcelona Clinic Liver Cancer; PLR, platelet to lymphocyte ratio; NLR, neutrophil to lymphocyte rate; LCR, lymphocyte C-reactive protein rate; LMR, lymphocyte to monocyte ratio; SII, systemic Immuneinflammation Index; CAR, C-reactive protein to albumin ratio; GPS, Glasgow prognostic score; mGPS, modified Glasgow prognostic score; PI, prognostic index; PNI, prognostic nutritional index; PD-I, programmed cell death protein I; TACE, transcatheter arterial chemoembolization; HAIC, hepatic infusion chemotherapy; TKIs, tyrosine kinase inhibitors.

\section{Relationships Between the PNI Score and Clinical Characteristics and Efficacy}

The correlations between clinical characteristics and efficacy and the PNI score are shown in Table 5. A high PNI score was associated with worse aspartate aminotransferase (AST) $(\mathrm{P}<0.001)$, ALB $(\mathrm{P}<0.001)$, TBIL $(\mathrm{P}<0.001)$, and Child-Pugh grade $(\mathrm{P}<0.001)$; increased CRP $(\mathrm{P}<0.001)$ and protein induced by vitamin $\mathrm{K}$ absence or antagonist-II (PIVKA-II) $(\mathrm{P}=$ $0.011)$; and larger tumor size $(\mathrm{P}<0.001)$, multiple lesions $(\mathrm{P}=0.020)$, and macrovascular invasion $(\mathrm{P}=$ 0.004). Tumor response analysis indicated that the objective response rate (ORR) $(34.9 \%$ vs $21.1 \%, \mathrm{P}=$ $0.001)$ and disease control rate (DCR) $(75.5 \%$ vs $59.6 \%, \mathrm{P}<0.001)$ were higher in the low PNI group.

\section{Discussion}

It is widely acknowledged that inflammation-based scores are associated with cancer-specific survival, but the inflammatory biomarkers that best predict prognosis in anti-PD-1 therapy, especially in HCC patients, remains unclear. To the best of our knowledge, this is the first study to comprehensively identify the correlation between inflammation scoring systems and the OS of HCC patients who received anti-PD-1 therapy. Moreover, the PNI score was found to be superior to the other inflammation-based scores in prediction.

HCC is an inflammation-driven carcinoma, for the majority of HCC arises in the context of chronic 
Table 3 Univariate and Multivariate Time-Dependent Cox Regression Analyses of the Prognostic Factors for Overall Survival

\begin{tabular}{|c|c|c|c|c|c|c|}
\hline \multirow[t]{3}{*}{ Variables } & \multicolumn{6}{|c|}{ Overall Survival } \\
\hline & \multicolumn{3}{|c|}{ Univariate Analysis } & \multicolumn{3}{|c|}{ Multivariate Analysis } \\
\hline & HR & $95 \% \mathrm{Cl}$ & $P$ & HR & $95 \% \mathrm{Cl}$ & $P$ \\
\hline Age, y $(\leq />50)$ & 0.812 & $0.613-1.076$ & 0.146 & & & \\
\hline Gender (male/female) & 1.159 & $0.750-1.79 \mid$ & 0.507 & & & \\
\hline Hepatitis B(no/yes) & 1.004 & $0.687-1.467$ & 0.984 & & & \\
\hline HBV-DNA copies $\left(\leq 1>10^{3}\right)$ & 1.153 & $0.868-1.532$ & 0.325 & & & \\
\hline ALT, U/L, $(\leq />50)$ & 1.225 & $0.925-1.622$ & 0.157 & & & \\
\hline AST, U/L, $(\leq />40)$ & 2.058 & $1.515-2.794$ & $<0.001$ & & & \\
\hline ALB, g/L, $(\leq />35)$ & 0.568 & $0.404-0.800$ & 0.001 & & & \\
\hline TBIL, umol/L, $(\leq />\mid 7.1)$ & 1.615 & $1.210-2.156$ & 0.001 & 1.406 & $1.044-1.892$ & 0.025 \\
\hline AFP, ng/mL $(\leq />400)$ & 1.596 & $1.200-2.122$ & 0.001 & & & \\
\hline PIVKA-II, mAU/mL, ( $/>400)$ & 1.512 & I.103-2.073 & 0.010 & & & \\
\hline Child-Pugh Grade (A/B) & 2.557 & $1.653-3.955$ & $<0.001$ & & & \\
\hline$B C L C$ stage $(A-B / C)$ & 1.469 & $1.038-2.080$ & 0.030 & 1.711 & $1.206-2.437$ & 0.003 \\
\hline Largest tumor size, $\mathrm{cm}(\leq />\mid 0)$ & 2.327 & I.754-3.087 & $<0.001$ & 2.090 & $1.568-2.787$ & $<0.001$ \\
\hline Tumor number $(|/>|)$ & 1.846 & $1.318-2.586$ & $<0.001$ & 1.747 & $1.246-2.450$ & 0.001 \\
\hline Macrovascular invasion (no/yes) & 1.613 & $1.210-2.150$ & 0.001 & & & \\
\hline Extrahepatic metastasis (no/yes) & $1.34 \mathrm{I}$ & $1.012-1.776$ & 0.041 & & & \\
\hline Previous treatment (no/yes) & 1.021 & $0.772-1.352$ & 0.883 & & & \\
\hline Combination therapy (no/yes) & 0.735 & $0.486-1.111$ & 0.144 & & & \\
\hline $\operatorname{PLR}(0 / 1)$ & 1.691 & $|.276-2.24|$ & $<0.001$ & & & \\
\hline NLR $(0 / I)$ & 1.714 & I.292-2.274 & $<0.001$ & & & \\
\hline $\operatorname{LCR}(0 / \mathrm{I})$ & 1.585 & $1.185-2.121$ & 0.002 & & & \\
\hline LMR (0/I) & 1.407 & $1.069-1.852$ & 0.015 & & & \\
\hline SII (0/I) & 2.049 & $1.315-3.194$ & 0.002 & & & \\
\hline $\operatorname{CAR}(0 / 1)$ & 1.582 & I.194-2.097 & 0.001 & & & \\
\hline \multicolumn{7}{|l|}{ GPS } \\
\hline 0 & Refence & Refence & Refence & & & \\
\hline 1 & 1.420 & $1.048-1.923$ & 0.024 & & & \\
\hline 2 & 2.021 & $1.323-3.086$ & 0.001 & & & \\
\hline \multicolumn{7}{|l|}{ mGPS } \\
\hline 0 & Refence & Refence & Refence & & & \\
\hline 1 & 1.513 & I.II4-2.055 & 0.008 & & & \\
\hline 2 & 2.127 & I.382-3.272 & 0.001 & & & \\
\hline
\end{tabular}

(Continued) 
Table 3 (Continued).

\begin{tabular}{|c|c|c|c|c|c|c|}
\hline \multirow[t]{3}{*}{ Variables } & \multicolumn{6}{|c|}{ Overall Survival } \\
\hline & \multicolumn{3}{|c|}{ Univariate Analysis } & \multicolumn{3}{|c|}{ Multivariate Analysis } \\
\hline & HR & $95 \% \mathrm{Cl}$ & $P$ & HR & $95 \% \mathrm{Cl}$ & $\mathbf{P}$ \\
\hline \multicolumn{7}{|l|}{ PI } \\
\hline 0 & Refence & Refence & Refence & & & \\
\hline 1 & $1.55 \mathrm{I}$ & $1.127-2.134$ & 0.007 & & & \\
\hline 2 & 2.593 & $1.592-4.222$ & $<0.001$ & & & \\
\hline PNI & 2.153 & $1.611-2.876$ & $<0.001$ & 1.770 & $1.309-2.393$ & $<0.001$ \\
\hline
\end{tabular}

Note: $\mathrm{P}$-value $<0.05$ is statistically significant in both univariate and multivariate analyses.

Abbreviations: $\mathrm{HR}$, hazard rate; $\mathrm{Cl}$, confidence interval; HBV, Hepatitis B virus; ALT, alanine aminotransferase; AST, aspartate aminotransferase; ALB, albumin; TBIL, total bilirubin; AFP, alpha fetoprotein; PIVKA-II, protein induced by vitamin K absence or antagonist-II; BCLC, Barcelona Clinic Liver Cancer; PLR, platelet to lymphocyte ratio; NLR, neutrophil to lymphocyte rate; LCR, lymphocyte C-reactive protein rate; LMR, lymphocyte to monocyte ratio; SII, systemic Immune-inflammation Index; CAR, C-reactive protein to albumin ratio; GPS, Glasgow prognostic score; mGPS, modified Glasgow prognostic score; PI, prognostic index; PNI, prognostic nutritional index.

inflammation and within a fibrotic liver. ${ }^{23,24}$ Emerging evidence has shown that the inflammatory response is correlated with the efficacy of anti-PD-1 therapy in advanced cancers. ${ }^{9,25,26}$ The unique immunobiology of the liver under conditions of fibrosis and chronic inflammation presents an opportunity for therapeutic targeting with immune checkpoint inhibitors, such as PD-1 inhibitors. ${ }^{24}$ A study proposed a tumor inflammation signature constructed with 18 genes that accurately predicted the benefit of patients treated with PD-1 inhibitors. ${ }^{27}$ However, the practicability of the model is insufficient in clinical practice. For HCC, the NLR and PLR were reported to have strong predictive roles in anti-PD-1 therapy, ${ }^{20,28,29}$ which was verified in our study. With the combination of albumin and lymphocytes, our study suggested that the presence of the systemic inflammatory response revealed by PNI was the optimal tool in the assessment of survival in HCC patients treated with PD-1 inhibitors compared with the other inflammation-based scores. The PNI score is measured using an inexpensive, easily available, simplified approach in clinical practice to stratify HCC patients with anti-PD-1 therapy into different risk groups.

The PNI score has been demonstrated to be an effective prognostic predictor in many types of digestive system cancers, including HCC. ${ }^{30}$ The underlying mechanism has not been well clarified. In this study, one possible explanation is that the decrease in lymphocytes indicates a weakening of immunity. ${ }^{31}$ In addition, the depletion of lymphocytes, such as CD4and CD8-positive $\mathrm{T}$ cells, is the key to immunosuppression. ${ }^{32}$ Lymphocytes within the tumor microenvironment seem to be critical in determining the efficacy of immune surveillance and lethality. ${ }^{33} \mathrm{On}$ the other hand, albumin reflects liver function, which determines the sustainability of immunotherapy and prognosis in HCC patients. Albumin is an indicator of nutritional status. A study indicated that nutrition and metabolism in patients with advanced HCC were closely related to anti-PD-1 treatment efficacy as well as survival benefit. ${ }^{34}$ Low serum albumin levels reflect a state of malnutrition, which would weaken cellular and humoral immunity, phagocytic functions, and other defense mechanisms in patients with cancer. ${ }^{35}$

This study has some limitations. First, this was a retrospective study conducted on a single-center cohort in China. A majority of the included patients had hepatitis B-related HCC. Since hepatitis C virus infection, alcohol abuse and an unbalanced diet are the leading causes of HCC in Japan, the United States, and European countries, the results need to be validated in external institutions with different disease backgrounds. Second, we used measures to control the consistency of each inflammation-based score; however, the best cutoff value of PNI in this study is not widely accepted (for the most common cutoff value is 45). If necessary, it should be revalidated and redefined 


\section{A}

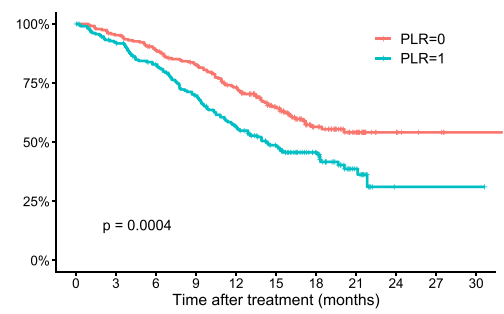

Number at risk

PLR=0| $\begin{array}{lllllllllll}232 & 220 & 201 & 183 & 156 & 112 & 60 & 32 & 9 & 4 & 1\end{array}$

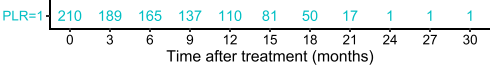

D

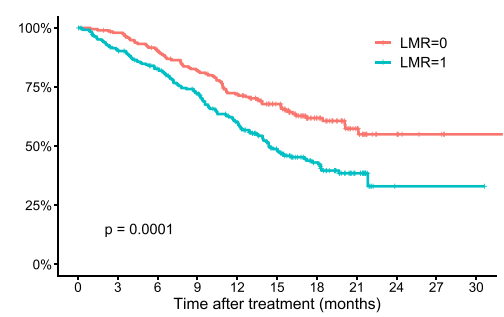

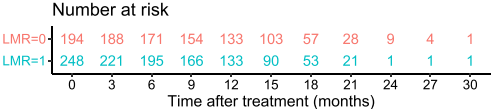

\section{G}

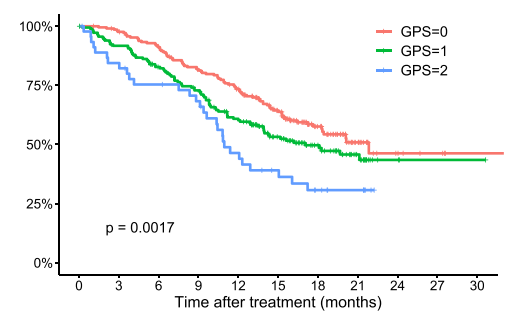

Number at risk

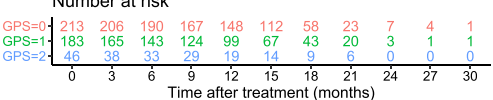

$J$

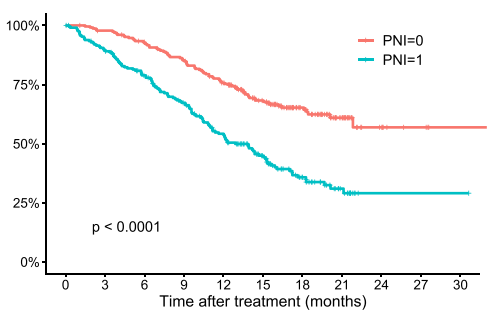

Number at risk

$\mathrm{PNN}=0 . \begin{array}{lllllllllll}229 & 221 & 207 & 189 & 165 & 126 & 73 & 33 & 9 & 4 & 1\end{array}$

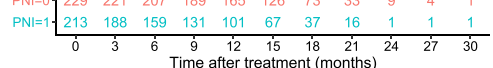

B

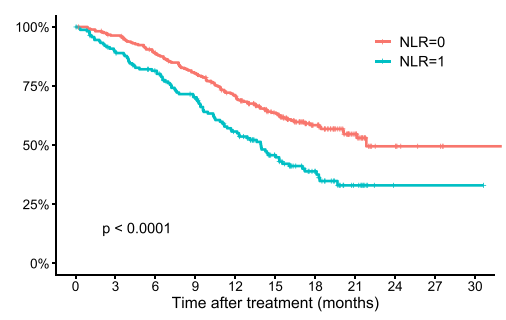

Number at risk

NLR=0- $\begin{array}{lllllllllll}277 & 264 & 240 & 216 & 187 & 142 & 80 & 38 & 9 & 4 & 1\end{array}$

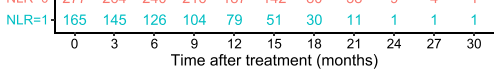

E

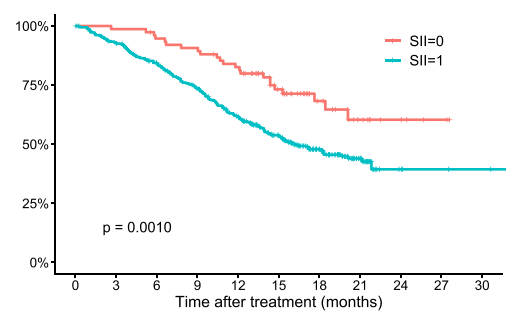

Number at risk

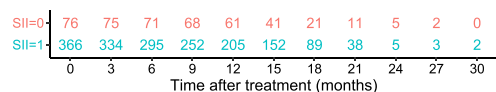

\section{H}

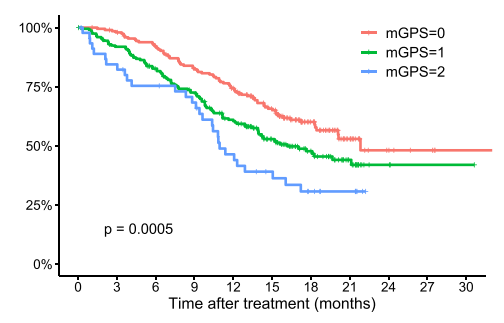

Number at risk

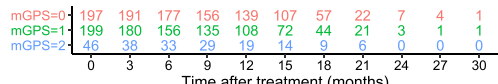

C

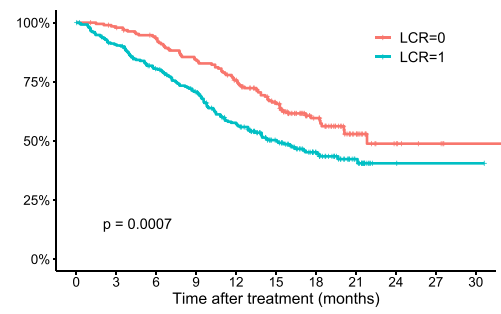

Number at risk

LCR=0- $\begin{array}{lllllllllll}191 & 185 & 173 & 155 & 137 & 105 & 56 & 25 & 8 & 4 & 1\end{array}$

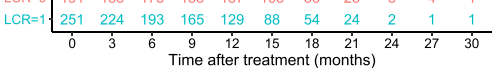

$\mathbf{F}$

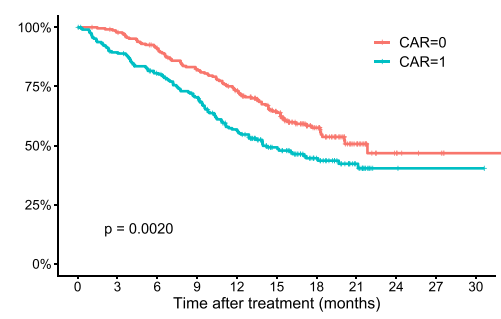
Number at risk

CAR=0- $\begin{array}{lllllllllll}232 & 225 & 205 & 182 & 160 & 121 & 65 & 27 & 8 & 4 & 1\end{array}$

CAR $=1 .$\begin{tabular}{|ccccccccccc}
210 & 184 & 161 & 138 & 106 & 72 & 45 & 22 & 2 & 1 & 1 \\
\hline 0 & $\mathbf{3}$ & $\mathbf{6}$ & $\dot{9}$ & $\mathbf{1} 2$ & $\mathbf{1 5}$ & $\mathbf{1 8}$ & $\mathbf{2 1}$ & $\mathbf{2} 4$ & $\mathbf{2} 7$ & $\mathbf{3 0}$
\end{tabular}

I

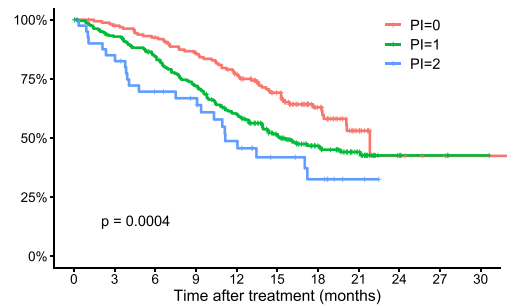

Number at risk

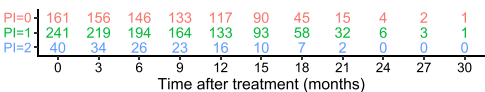

Figure I Kaplan-Meier curves of the overall survival of HCC patients after anti-PD-I therapy. (A) PLR, (B) NLR, (C) LCR, (D) LMR, (E) SII, (F) CAR, (G) GPS, (H) mGPS, (I) PI and (J) PNI. 


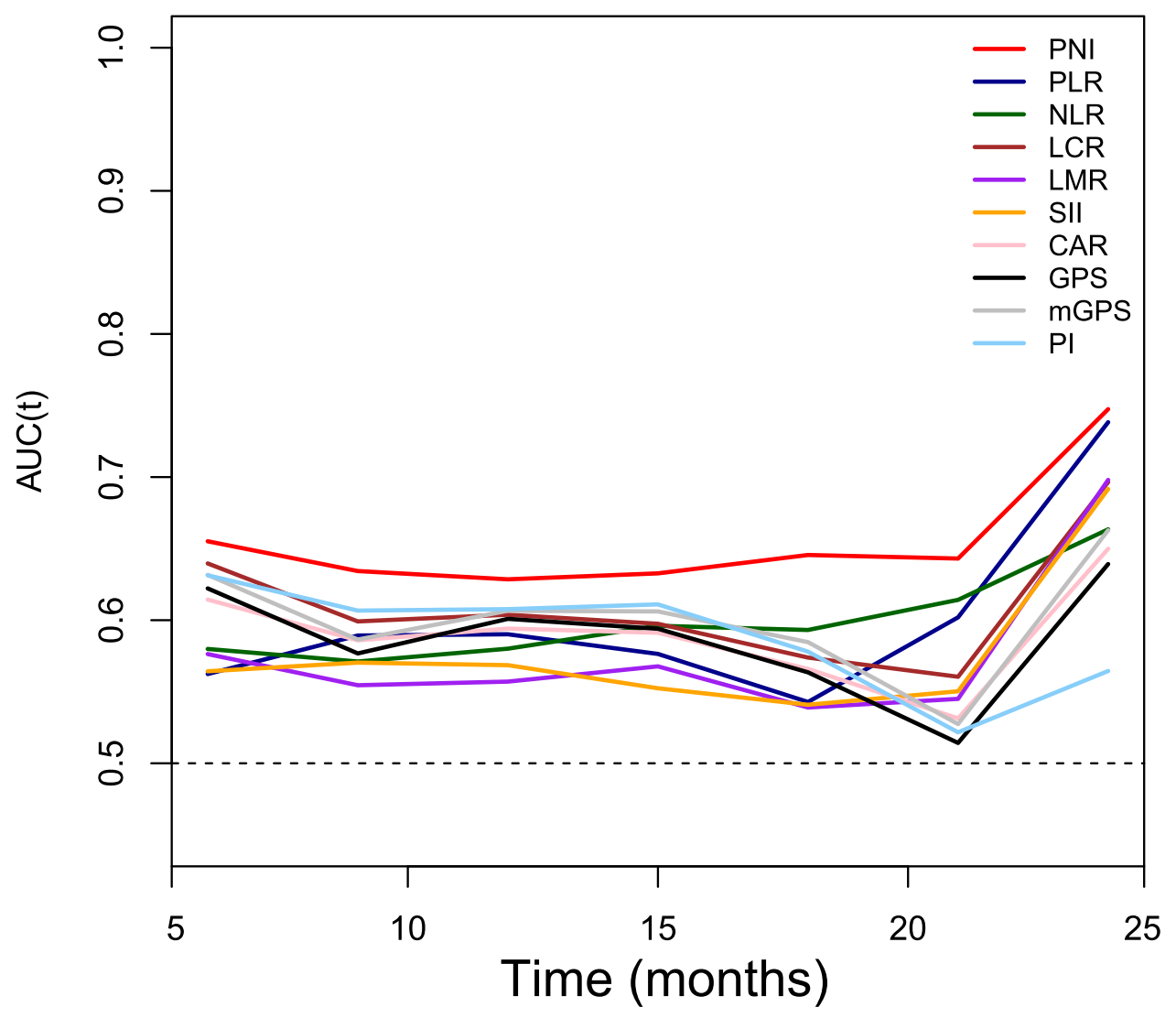

Figure 2 Time-dependent AUC plot for survival prediction of inflammation-based scores.

in future studies with authoritative sources. Third, patients received non-single PD-1 inhibitors during the whole treatment, which inevitably caused bias. Finally, the underlying potential regulatory mechanism of albumin and lymphocytes on immunotherapy has not been elucidated and deserves further investigation.

\section{Conclusions}

Our study demonstrated that the PNI score was an independent prognostic indicator in $\mathrm{HCC}$ patients receiving anti-PD-1 therapy and performed well compared with the other inflammation-based scores. This is an easy-to-use tool for risk stratification and benefits physicians in the

Table 4 Concordance Index for the Comparison of Different Inflammatory-Based Scores

\begin{tabular}{|l|c|c|c|c|c|}
\hline Scores & 6-Month AUROC & I 2-Month AUROC & I8-Month AUROC & 24-Month AUROC & C-Index \\
\hline PNI & $0.66(0.60-0.72)$ & $0.63(0.57-0.69)$ & $0.65(0.59-0.70)$ & $0.75(0.69-0.8 I)$ & $0.65(0.62-0.68)$ \\
PLR & $0.56(0.49-0.63)$ & $0.59(0.53-0.65)$ & $0.54(0.49-0.60)$ & $0.73(0.66-0.80)$ & $0.59(0.56-0.62)$ \\
NLR & $0.58(0.50-0.66)$ & $0.58(0.52-0.64)$ & $0.59(0.53-0.64)$ & $0.66(0.60-0.72)$ & $0.59(0.56-0.62)$ \\
LCR & $0.64(0.57-0.7 I)$ & $0.60(0.55-0.66)$ & $0.58(0.52-0.63)$ & $0.69(0.64-0.74)$ & $0.60(0.57-0.63)$ \\
LMR & $0.58(0.50-0.66)$ & $0.56(0.50-0.61)$ & $0.54(0.49-0.60)$ & $0.70(0.56-0.74)$ & $0.57(0.54-0.60)$ \\
SII & $0.57(0.49-0.64)$ & $0.57(0.51-0.63)$ & $0.54(0.48-0.60)$ & $0.69(0.64-0.74)$ & $0.57(0.55-0.59)$ \\
CAR & $0.61(0.53-0.69)$ & $0.60(0.54-0.65)$ & $0.57(0.5 I-0.62)$ & $0.65(0.59-0.7 I)$ & $0.59(0.56-0.62)$ \\
GPS & $0.62(0.54-0.69)$ & $0.60(0.54-0.66)$ & $0.56(0.50-0.62)$ & $0.64(0.59-0.70)$ & $0.59(0.57-0.62)$ \\
mGPS & $0.63(0.55-0.70)$ & $0.61(0.55-0.67)$ & $0.58(0.52-0.63)$ & $0.66(0.60-0.72)$ & $0.60(0.57-0.63)$ \\
PI & $0.63(0.56-0.7 I)$ & $0.61(0.55-0.67)$ & $0.58(0.52-0.64)$ & $0.56(0.51-0.61)$ & $0.60(0.57-0.63)$ \\
\hline
\end{tabular}

Note: values are presented as the AUROC ( $95 \%$ confidence interval).

Abbreviations: AUROC, area under the receiver operating characteristic curve; PNI, prognostic nutritional index; PLR, platelet to lymphocyte ratio; NLR, neutrophil to lymphocyte rate; LCR, lymphocyte C-reactive protein rate; LMR, lymphocyte to monocyte ratio; SII, systemic Immune-inflammation Index; CAR, C-reactive protein to albumin ratio; GPS, Glasgow prognostic score; mGPS, modified Glasgow prognostic score; PI, prognostic index. 
Table 5 Baseline Characteristics of the Patients Grouped by PNI Score

\begin{tabular}{|c|c|c|c|}
\hline \multirow[t]{2}{*}{ Variables } & PNI $=0$ & PNI = I & \multirow[t]{2}{*}{$\mathbf{P}$} \\
\hline & $N=229$ & $N=213$ & \\
\hline Age, y & $50(23-75)$ & $54(2 \mathrm{I}-75)$ & 0.009 \\
\hline Gender (male/female) & $195 / 34(85.2 / 14.8)$ & $187 / 26(87.8 / 12.2)$ & 0.418 \\
\hline Hepatitis (no/yes) & $37 / 192(16.2 / 83.8)$ & $33 / 180(15.5 / 84.5)$ & 0.848 \\
\hline HBV-DNA copies & $198\left(0-6.7 \times 10^{6}\right)$ & $989\left(0-2.2 \times 10^{8}\right)$ & 0.119 \\
\hline WBC $\left(10^{9} / \mathrm{L}\right)$ & $6.6(2.7-15.3)$ & $6.0(2.3-17.2)$ & 0.864 \\
\hline ALT, U/L, $(\leq />50)$ & $40.4(5.6-520.3)$ & $45.9(9.1-263.8)$ & 0.187 \\
\hline AST, U/L, $(\leq />40)$ & $47.2(14.5-728.1)$ & $67.9(17.6-893.4)$ & $<0.001$ \\
\hline ALB, g/L, $(\leq />35)$ & $43.6(34.0-52.4)$ & $37.2(24.5-44.6)$ & $<0.001$ \\
\hline TBIL, umol/L, $(\leq />17.1)$ & $13.0(4.0-54.2)$ & I7.I (4.2-I I4.3) & $<0.001$ \\
\hline CRP, mg/L & $5.8(0.08-263.5)$ & $18.7(0.5-223.4)$ & $<0.001$ \\
\hline AFP, ng/mL & $418(1.9-121,000)$ & $1129(1.4-121,000)$ & 0.218 \\
\hline PIVKA-II, mAU/mL & $2246(19-75,000)$ & $7607(16-75,000)$ & 0.011 \\
\hline Child-Pugh Grade (A/B) & $227 / 2(99.1 / 0.9)$ & $183 / 30(85.9 / 14.1)$ & $<0.001$ \\
\hline BCLC Stage $(A / B / C)$ & $24 / 41 / 164(10.5 / 17.9 / 7 \mid .6)$ & $15 / 43 / 155(7.0 / 20.2 / 72.8)$ & 0.406 \\
\hline Largest tumor size, $\mathrm{cm}(\leq />\mid 0)$ & $8.0(1.0-21.5)$ & $10.1(1.0-20.3)$ & $<0.001$ \\
\hline Tumor number $(|/>|)$ & $85 / 144(37.1 / 62.9)$ & $57 / 156(26.8 / 73.2)$ & 0.020 \\
\hline Macrovascular invasion (no/yes) & $124 / 105(54.1 / 45.9)$ & $86 / 127(40.4 / 59.6)$ & 0.004 \\
\hline Extrahepatic metastasis (no/yes) & | $31 / 98(57.2 / 42.8)$ & $135 / 78(63.4 / 36.6)$ & 0.185 \\
\hline Cycles of anti-PD-I & $5(I-25)$ & $3(I-25)$ & $<0.001$ \\
\hline \multicolumn{4}{|l|}{ Previous treatment } \\
\hline Surgery & $42(18.3)$ & $20(9.4)$ & 0.007 \\
\hline TACE & $49(21.4)$ & $41(19.2)$ & 0.575 \\
\hline HAIC & $39(17.0)$ & $54(25.4)$ & 0.032 \\
\hline Ablation & $26(11.4)$ & $12(5.6)$ & 0.032 \\
\hline TKIs* & $28(12.2)$ & $22(10.3)$ & 0.529 \\
\hline \multicolumn{4}{|l|}{ Best tumor response** } \\
\hline CR & II (4.8) & $6(2.8)$ & 0.278 \\
\hline PR & $69(30.1)$ & $39(18.3)$ & 0.004 \\
\hline SD & $93(40.6)$ & $82(38.5)$ & 0.708 \\
\hline PD & $33(14.4)$ & $38(17.8)$ & 0.326 \\
\hline NA & $23(10.1)$ & $48(22.5)$ & 0.001 \\
\hline ORR & $80(34.9)$ & $45(21.1)$ & 0.001 \\
\hline DCR & $173(75.5)$ & $127(59.6)$ & $<0.001$ \\
\hline
\end{tabular}

Notes: values are presented as the median (range) or $\mathrm{n}(\%)$. P-value $<0.05$ is statistically significant. *TKls include sorafenib, lenvatinib, regorafenib, apatinib. **Tumor response were evaluated according to mRESIST criterion.

Abbreviations: PNI, prognostic nutritional index; HBV, Hepatitis B virus; WBC, white blood cell; ALT, alanine aminotransferase; AST, aspartate aminotransferase; ALB, albumin; TBIL, total bilirubin; CRP, C-reactive protein; AFP, alpha fetoprotein; PIVKA-II, protein induced by vitamin K absence or antagonist-II; BCLC, Barcelona Clinic Liver Cancer; PLR, platelet to lymphocyte ratio; NLR, neutrophil to lymphocyte rate; LCR, lymphocyte C-reactive protein rate; LMR, lymphocyte to monocyte ratio; SII, systemic Immune-inflammation Index; CAR, C-reactive protein to albumin ratio; GPS, Glasgow prognostic score; mGPS, modified Glasgow prognostic score; PI, prognostic index; PD-I, programmed cell death protein I; TACE, transcatheter arterial chemoembolization; HAIC, hepatic infusion chemotherapy; CR, complete response; PR, partial response; SD, stable disease; PD, progressive disease; NA, not assessed; ORR, objective response rate; DCR, disease control rate; TKIs, tyrosine kinase inhibitors.

selection of therapeutic strategies for anti-PD-1 treatment in HCC patients.

\section{Data Sharing Statement}

The data are available from the Sun Yat-sen University Cancer Center Institutional Data Access/Ethics Committee for researchers. The data sets used during the present study are available from the corresponding authors on reasonable request.

\section{Ethics Approval Statement}

This study was conducted according to the ethical guidelines of the 1975 Declaration of Helsinki. This research was approved by the institutional review board of Sun Yat-sen 
University Cancer Center (RDDA2020001831). Patient informed consent is exempt because the study used retrospective anonymous clinical data that were obtained after each patient agreed to treatment. Individuals cannot be identified based on the data presented. We declare to ensure the confidentiality of patient data.

\section{Acknowledgments}

Authors thank AJE for English polishing.

\section{Author Contributions}

All authors made a significant contribution to the work reported, whether that is in the conception, study design, execution, acquisition of data, analysis and interpretation, or in all these areas; took part in drafting, revising or critically reviewing the article; gave final approval of the version to be published; have agreed on the journal to which the article has been submitted; and agree to be accountable for all aspects of the work.

\section{Funding}

This study was supported by the National Natural Science Foundation of China (No. 81871985); Natural Science Foundation of Guangdong Province (No. 2018A0303130098 and 2017A030310203); Science and Technology Planning Project of Guangdong Province (No. 2017A020215112); Medical Scientific Research Foundation of Guangdong Province (No. A2017477); Science and Technology Planning Project of Guangzhou (No.201903010017 and No. 201904010479); Clinical Trials Project (5010 Project) of Sun Yat-sen University (No. 5010-2017009).

\section{Disclosure}

The authors have no conflicts of interest to declare.

\section{References}

1. Sung H, Ferlay J, Siegel RL, et al. Global cancer statistics 2020: GLOBOCAN estimates of incidence and mortality worldwide for 36 cancers in 185 countries. CA Cancer J Clin. 2021;71(3):209-249. doi: $10.3322 /$ caac. 21660

2. Roayaie S, Jibara G, Tabrizian P, et al. The role of hepatic resection in the treatment of hepatocellular cancer. Hepatology. 2015;62 (2):440-451. doi:10.1002/hep. 27745

3. Zhu XD, Sun HC. Emerging agents and regimens for hepatocellular carcinoma. J Hematol Oncol. 2019;12(1):110. doi:10.1186/s13045019-0794-6

4. El-Khoueiry AB, Sangro B, Yau T, et al. Nivolumab in patients with advanced hepatocellular carcinoma (CheckMate 040): an open-label, non-comparative, Phase 1/2 dose escalation and expansion trial. Lancet. 2017;389(10088):2492-2502. doi:10.1016/S0140-6736(17) $31046-2$
5. Zhu AX, Finn RS, Edeline J, et al. Pembrolizumab in patients with advanced hepatocellular carcinoma previously treated with sorafenib (KEYNOTE-224): a non-randomised, open-label phase 2 trial. Lancet Oncol. 2018;19(7):940-952. doi:10.1016/S1470-2045(18) 30351-6

6. Hanahan D, Weinberg RA. Hallmarks of cancer: the next generation. Cell. 2011;144(5):646-674. doi:10.1016/j.cell.2011.02.013

7. Diakos CI, Charles KA, McMillan DC, Clarke SJ. Cancer-related inflammation and treatment effectiveness. Lancet Oncol. 2014;15 (11):e493-e503. doi:10.1016/S1470-2045(14)70263-3

8. Crusz SM, Balkwill FR. Inflammation and cancer: advances and new agents. Nat Rev Clin Oncol. 2015;12(10):584-596. doi:10.1038/ nrclinonc.2015.105

9. Nakamura K, Smyth MJ. Targeting cancer-related inflammation in the era of immunotherapy. Immunol Cell Biol. 2017;95(4):325-332. doi:10.1038/icb.2016.126

10. Zhao QT, Yuan Z, Zhang H, et al. Prognostic role of platelet to lymphocyte ratio in non-small cell lung cancers: a meta-analysis including 3720 patients. Int $J$ Cancer. 2016;139(1):164-170. doi:10.1002/ijc. 30060

11. Grenader T, Waddell T, Peckitt C, et al. Prognostic value of neutrophil-to-lymphocyte ratio in advanced oesophago-gastric cancer: exploratory analysis of the REAL-2 trial. Ann Oncol. 2016;27 (4):687-692. doi:10.1093/annonc/mdw012

12. Okugawa Y, Toiyama Y, Yamamoto A, et al. Lymphocyte-C-reactive protein ratio as promising new marker for predicting surgical and oncological outcomes in colorectal cancer. Ann Surg. 2020;272 (2):342-351. doi:10.1097/SLA.0000000000003239

13. Chan JC, Chan DL, Diakos CI, et al. The lymphocyte-to-monocyte ratio is a superior predictor of overall survival in comparison to established biomarkers of resectable colorectal cancer. Ann Surg. 2017;265(3):539-546. doi:10.1097/SLA.0000000000001743

14. Hu B, Yang XR, Xu Y, et al. Systemic immune-inflammation index predicts prognosis of patients after curative resection for hepatocellular carcinoma. Clin Cancer Res. 2014;20(23):6212-6222. doi:10.1158/1078-0432.CCR-14-0442

15. Ishizuka M, Nagata H, Takagi K, Iwasaki Y, Shibuya N, Kubota K. Clinical significance of the c-reactive protein to albumin ratio for survival after surgery for colorectal cancer. Ann Surg Oncol. 2016;23 (3):900-907. doi:10.1245/s10434-015-4948-7

16. Bruixola G, Caballero J, Papaccio F, et al. Prognostic Nutritional Index as an independent prognostic factor in locoregionally advanced squamous cell head and neck cancer. ESMO Open. 2018;3(6): e000425. doi:10.1136/esmoopen-2018-000425

17. McMillan DC. The systemic inflammation-based Glasgow Prognostic Score: a decade of experience in patients with cancer. Cancer Treat Rev. 2013;39(5):534-540. doi:10.1016/j.ctrv.2012.08.003

18. Proctor MJ, Morrison DS, Talwar D, et al. An inflammation-based prognostic score (mGPS) predicts cancer survival independent of tumour site: a Glasgow Inflammation Outcome Study. Br J Cancer. 2011;104(4):726-734. doi:10.1038/sj.bjc.6606087

19. Gruber ES, Jomrich G, Kaider A, Gnant M, Sahora K, Schindl M. The prognostic index independently predicts survival in patients with pancreatic ductal adenocarcinoma undergoing resection. Ann Surg Oncol. 2020;27(6):2017-2024. doi:10.1245/s10434-019-08161-6

20. Dharmapuri S, Ozbek U, Lin JY, et al. Predictive value of neutrophil to lymphocyte ratio and platelet to lymphocyte ratio in advanced hepatocellular carcinoma patients treated with anti-PD-1 therapy. Cancer Med. 2020;9(14):4962-4970. doi:10.1002/cam4.3135

21. Bruix J, Reig M, Sherman M. Evidence-based diagnosis, staging, and treatment of patients with hepatocellular carcinoma. Gastroenterology. 2016;150(4):835-853. doi:10.1053/j. gastro.2015.12.041

22. Llovet JM, Lencioni R. mRECIST for HCC: performance and novel refinements. $J$ Hepatol. 2020;72(2):288-306. doi:10.1016/j. jhep.2019.09.026 
23. Cabillic F, Corlu A. Regulation of transdifferentiation and retrodifferentiation by inflammatory cytokines in hepatocellular carcinoma. Gastroenterology. 2016;151(4):607-615. doi:10.1053/j. gastro.2016.06.052

24. Keenan BP, Fong L, Kelley RK. Immunotherapy in hepatocellular carcinoma: the complex interface between inflammation, fibrosis, and the immune response. $J$ Immunother Cancer. 2019;7(1):267. doi:10.1186/s40425-019-0749-z

25. Hill M, Segovia M, Russo S, Girotti MR, Rabinovich GA. The paradoxical roles of inflammation during PD-1 blockade in cancer. Trends Immunol. 2020;41(11):982-993. doi:10.1016/j.it.2020.09.003

26. Macciò A, Madeddu C. Blocking inflammation to improve immunotherapy of advanced cancer. Immunology. 2019;159(4):357-364. doi:10.1111/imm.13164

27. Damotte D, Warren S, Arrondeau J, et al. The tumor inflammation signature (TIS) is associated with anti-PD-1 treatment benefit in the CERTIM pan-cancer cohort. J Transl Med. 2019;17(1):357. doi:10.1186/s12967-019-2100-3

28. Sangro B, Melero I, Wadhawan S, et al. Association of inflammatory biomarkers with clinical outcomes in nivolumab-treated patients with advanced hepatocellular carcinoma. $J$ Hepatol. 2020;73 (6):1460-1469. doi:10.1016/j.jhep.2020.07.026

29. Akce M, Liu Y, Zakka K, et al. Impact of sarcopenia, BMI, and inflammatory biomarkers on survival in advanced hepatocellular carcinoma treated with anti-PD-1 antibody. Am J Clin Oncol. 2021;44 (2):74-81. doi:10.1097/COC.0000000000000787
30. Sun K, Chen S, Xu J, Li G, He Y. The prognostic significance of the prognostic nutritional index in cancer: a systematic review and meta-analysis. J Cancer Res Clin Oncol. 2014;140(9):1537-1549. doi:10.1007/s00432-014-1714-3

31. Luo Y, Xie Y, Zhang W, et al. Combination of lymphocyte number and function in evaluating host immunity. Aging (Albany NY). 2019;11(24):12685-12707. doi:10.18632/aging.102595

32. Gehring AJ, Ho ZZ, Tan AT, et al. Profile of tumor antigen-specific CD8 T cells in patients with hepatitis B virus-related hepatocellular carcinoma. Gastroenterology. 2009;137(2):682-690. doi:10.1053/j. gastro.2009.04.045

33. Chraa D, Naim A, Olive D, Badou A. T lymphocyte subsets in cancer immunity: friends or foes. J Leukoc Biol. 2018;105(2):243-255. doi:10.1002/JLB.MR0318-097R

34. Jiang $Y$, Tu X, Zhang $X$, et al. Nutrition and metabolism status alteration in advanced hepatocellular carcinoma patients treated with anti-PD-1 immunotherapy. Support Care Cancer. 2020;28 (11):5569-5579. doi:10.1007/s00520-020-05478-x

35. Nakanishi Y, Masuda T, Yamaguchi K, et al. Albumin-globulin ratio is a predictive biomarker of antitumor effect of anti-PD-1 antibody in patients with non-small cell lung cancer. Int J Clin Oncol. 2020;25 (1):74-81. doi:10.1007/s10147-019-01539-2
Journal of Inflammation Research

\section{Publish your work in this journal}

The Journal of Inflammation Research is an international, peerreviewed open-access journal that welcomes laboratory and clinical findings on the molecular basis, cell biology and pharmacology of inflammation including original research, reviews, symposium reports, hypothesis formation and commentaries on: acute/chronic inflammation; mediators of inflammation; cellular processes; molecular
Dovepress

mechanisms; pharmacology and novel anti-inflammatory drugs; clinical conditions involving inflammation. The manuscript management system is completely online and includes a very quick and fair peerreview system. Visit http://www.dovepress.com/testimonials.php to read real quotes from published authors. 